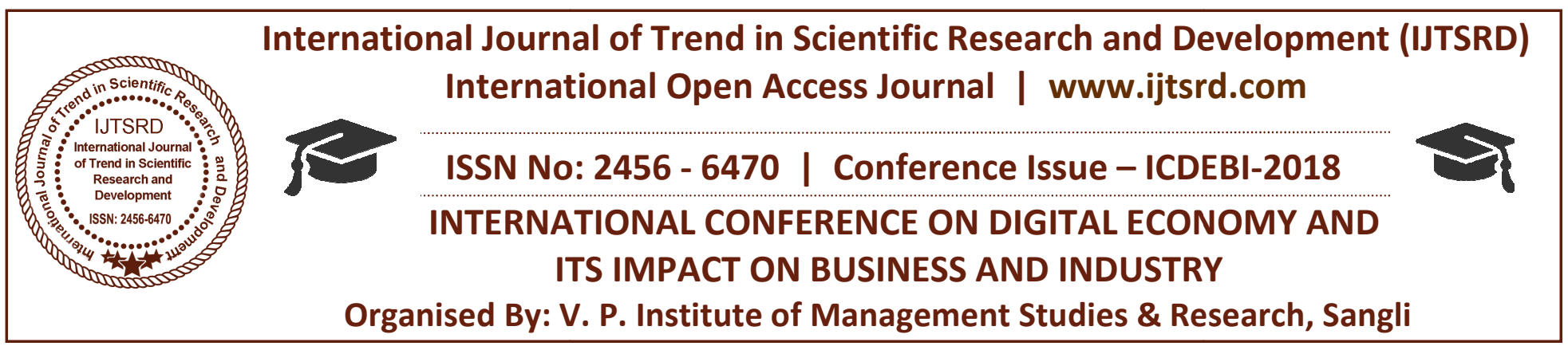

\title{
Digitisation in Banking
}

\author{
Samita V. Dalvi \\ Assistant Professor, V.P. Institute of Management Studies and Research, \\ Sangli, Maharashtra, India \\ Affiliated to Shivaji University, Kolhapur, Maharashtra, India
}

\begin{abstract}
A digital shift is taking place globally over wide range of sectors to stay ahead in the competition in their respective fields to which banking industry is no exception. Digitalization is inevitable for banking industry and hence "Hop on the digitalisation express" should be the goal of every bank in the world. The financial landscape is on the verge of change and has essentially revolutionised the business model of banking industry. In the new digital era, increasing expectations of the customers across all delivery channels, be it ATM, Internet banking or mobile banking is a standard requirement. Customer centric digitalised operations will increase the efficiency and effectiveness in banking services in the challenging, dynamic environment. Millenials are more eager to do their banking transactions and financial planning via e-banking and hence a key to success of banks is offering everything on electronic media. Projecting the banks offerings on third-party sites and providing value added services on mobile application using the open API economy will be crucial too. Not only are the Customers, the key players of digitalisation as the banks are constantly striving hard to remain one step ahead of customers but also the competitors and the regulatory agencies are acting as drivers to digitalisation. Customers expect a seamless multichannel experience and a consistent, global service from banking sector.
\end{abstract}

KEYWORDS: e banking, internet banking, mobile banking

\section{INTRODUCTION}

Digitalisation has transformed manual processes and transactions into digital services. Across all verticals, consumer needs have been met in entirely innovative ways. The government's drive towards making India a cash light digital economy and increasing revenues by empowering the citizens are in synergy. The wide scope of digital banking spans from, dealings from the front desk which customers experience and helps in building customer relationship, to the back end that bankers operate through their internal infrastructure and the bridge that connects the two ends .A digital bank facilitates at all functional levels of banking through all service delivery channels. Customer (CRM) is an integral part of a digital banking system, since it helps banks to directly communicate with their customers.

In today's world Digital is a buzzword and Banks have to stay in race to meet the ever increasing demands of new tech savy generation. Digital Banking is not only used for front desk operations like Internet Banking, Mobile Banking, Direct Banking, use of Social Media in Banking, Artificial Intelligence, Robotics, Chat-bots, Cognitive computing, Block-chain, Big Data, voice biometrics etc but also includes various back-end modernization programs integrated with front end users to achieve overall goals of digital Banking which includes legacy modernization, Integration, CRM, Document Imaging etc.

Due to accelerated technological improvements and fierce competition, banking sector is working under constant pressure. 


\section{History-}

In 1988, Reserve Bank of India set up a Committee on computerization in banks headed by Dr. C. Rangarajan. In late 1980, banks were urged to digitalise their operations, in order to improve the customer service and MIS reporting and hence started using Information Technology initially with the introduction of standalone PCs and migrated to Local Area Network (LAN) connectivity within the bank branch setup. With further advancement, banks adopted the Core Banking solution. Thus branch banking changed to bank banking. Core Banking Solution (CBS) enabled banks to enhance the customer servicing through anywhere and anytime banking. Different Core banking platforms such as Finacle designed by Infosys, BaNCS by TCS, FLEXCUBE by i-flex etc gained popularity during this time.

The process of Computerization gained pace with deregulation and liberalisation in 1991-92 which led to rising competition from private and foreign banks. Several commercial banks started moving towards digitalised customer services by adopting banking solutions by joint venturing with information technology firms.

RBI has been a driving force for Bank Mechanization and Automation with the introduction to MICR based cheque processing, Electronic Funds transfer, Interconnectivity among bank Branches and implementation of ATM (Automated Teller Machine) Channel . Strong guidelines from Reserve Bank of India have strengthened the Payment and Settlement systems in banks.

\section{Goals of digitalised banking -}

1. The goal of integrating banking services and technology is convenience, flexibility, simplicity and security of operations for customers and to meet the industry's rapidly rising customer expectations.

2. Targeting the new customers by way of innovative digitalized products

3. Moving from lifecycle banking to lifestyle banking where bank will remain a constant part of daily life of its customers providing ultimate personal and near real time solutions.

\section{Advantages of digitalisation -}

1. Huge saving in cost and time of banking Automated banking software solutions work in place of cumbersome, redundant manual labour. Traditional bank business processes are time consuming and costly and prone to human error. Hence banks need to implement BPR (business process reengineering) Paperless working will definitely reduce storage space cost as well as increase human efficiency due to qualitative digital data and faster sensitivity to changing market trends in the hyper dynamic macro environment.

e.g. E-banking has resulted in reducing costs to the extent that the cost of a bank transaction on Branch Banking is estimated to be in a range of Rs.70 to Rs. 75 while it is around Rs. 15 to Rs.16 on ATM, Rs.2 or less on Online Banking and Rs.1 or less on Mobile Banking.

2. Accurate and reliable operational performance with no scope for human error - The prerequisite for banks aspiring to digitalise their operations is financial accuracy. Traditional banking had $40 \%$ error rate which needed recomputing and was worsened with lack of IT integration between branch, Head office and back office adding up to complexities in verification and authentication procedure.

3. Faster speed of delivery channels - customers are enjoying round the clock connection with banks and availability of services at the fastest speed.

4. Improved customer satisfaction and relationships due to 24/7 support availability, customer follow up process automation.

5. Acquisition and retaining of customers thereby achieving leadership in competitive environment. - The fierce competition ultimately aiming to increase customer strength results due to CRM solutions that assist the banks to maintain closer relationships with tech savvy consumers. Banks maintain pool of data containing customer history therby facilitating quick access to email and other forms of online communication. Banks can effectively utilise customer reward programmes for continued loyalty and satisfaction of customers.

6. Cost effective for banks as well as customers. ATMs help banks reduce overhead costs, especially if they are available at various strategic locations beyond branch offices. Banks can take data-driven dynamic decisions with the aid of digital analytics which lend helping hand to both customers and banks. 
7. Business efficiency-Reduced cost and enhanced speed improve the efficiency of internal functions leading to increased human productivity.

8. Transparency is ensured due to which problems of fake currency or black money will dissolve.

9. Approaching fast on the new horizon of cash-light India or a cashless future which excludes Paper money.

10. Customer centricity - In the pre digital era banks used to focus on pushing and selling the existing available products to customers but with digitalisation at the core of everyday life, the ultimate goal of banks is to make customer happy. Digital infrastructure provides billions of customers with affordable broadband and low-cost devices. Banks should focus on innovating new products and services that are meeting the changing expectations of customers, maintain competitive edge and match with the latest technology trends

11. Physical cash handling has reduced - possibility of misplacement of cash or the potential for money to be stolen is reduced to a great extent, additionally, digital cash can be traced and accounted for more accurately in cases of disputes. As consumers can purchase with the help of apps, there is less need to carry physical cash in their purses and handling large amount of cash can be avoided.

12. In the absence of personal intervention, all customers are treated at par, be it urban or rural .

13. Benefits to government: -

A. Digital transactions can be easily monitored and any payment made by any customer to any merchant will be recorded in the system. Thus there will be no means for illegal transactions. By prohibiting cash-based transactions and using only digital payments, the government can efficiently expel the black economy.

B. Increase in Revenues: In case of digital economy, when the transactions are digitized, monitoring sales and taxes becomes easy. Since each transaction is recorded, the customers will get a bill for their purchase, and the merchants are bound to pay the sales tax to the government. This, in turn, increases the revenue of the government, thus resulting in growth of the overall financial health of the country.

C. Empowerment to People: One of the greatest advantages of moving towards digitalisation is that it gives an empowerment to the citizens.
When the payments move digital, each and every individual is bound to have a bank account, a mobile phone, etc. This way, the government can easily transfer the subsidies directly to Aadhaar-linked bank accounts of people. In short, people no longer have to wait to receive the incentives and subsidies that they are bound to receive from the government. This feature is already in place in most cities. One example of that would be the LPG subsidy that government gives to the common people. This subsidy payment is done via bank transfers these days.

14. Risk management software can detect and respond to market changes more quickly than expert risk managers.

\section{Disadvantages of digitalisation -}

1. Though digitalisation leads to unemployment in one area but new jobs are created in IT sector, cyber security, research Team etc.

2. Large sections of Indians are digitally illiterate so they are not comfortable in digital banking.

3. Banking environment is more prone to hacks and cyber attacks as financial data is more vulnerable.

4. Some concrete bank branches may cease to exist with the increasing use of online banking.

\section{Requirements in digitalised banks -}

A. A vibrant digital future will need a strong underlying technology with right omni channel development platform which will incorporate features like easy app management, inbuilt security and strong feasibility.

B. The required infrastructure should provide mass data storage, infinite computing power, and pervasive connectivity, advanced analytical tools enabling the customer to perform their operations on one simple finger touch.

C. An integrated IT infrastructure is utmost essential .High speed and transparent processing of transactions which results in wide spectrum of products and security offered to the consumers at fair prices resulting into high quality relationships with banks.

D. The software solution should be flexible adapting to constant customisation and avoiding rigidity.

E. A strong in house IT team is a must.

\section{Challenges of digitalized banking-}

Banks are facing competition from non-banking companies as well as smaller Fintech companies. 
1. Cyber crime - Siphoning of funds on massive scale by cyber attackers is possible. Money and data security is at constant threat by hackers. All businesses big or small face growing cyber threats which damage image and reputations of the bank. The key challenge in the digital era is safeguarding the customers from cybercrimes with advanced cyber securities incorporated in the IT infrastructure of the bank.

2. Choice of technology-user's choice of device that will be used for smooth functioning is important .Office goers will prefer Laptops and desktops while those who travel for business prefer tablets and depend upon high quality cameras. Device compatibility with software plays crucial role. The customers are more enthusiastic to use full range of e-commerce financial services.

3. Achieving error free or flawless app-customers especially younger ones experience power while banking through smart phone applications. Keeping control over one's expenses and monitoring investments at any time and from any place in the world is the core benefit made available to customers by banking and financial applications .The organizations which fail to adopt this technological advancements to overcome the outdated approaches and inefficiently handled customer relationships will be out from competitive market and will not be able to retain the customers.

4. Targetting the new customers by way of innovative digitalized techniques can pose a problem to banking industry. Digital Banking Readiness Index (DiBrix) can be used in the process for evaluation.

5. Sustainability - Post successful innovation and implementation, the next challenge is sustaining as leader in the market

6. Quality and speed should go hand in hand- In the process of offering maximum financial products and services to widen customer base, it leads to compromises on quality of products. The challenges in fast paced and dynamic digital world are manifold.

7. The next phase of growth for cards is from the tap-and-pay feature, through NFC-enabled contactless technology where swiping or dipping a card is eliminated; instead payment can be made when it is brought close to either a PoS machine or card reader. These cards have become popular in Australia, UK and France especially for metro travel or toll-and-transit facilities
8. Good user experience on digital channels or user friendly nature is crucial to the overall customer experience and acceptance. And banks that neglect the digital channels are reducing their chances with their best customers. Poor digital experience could shift affluent customers towards other alternatives, whereas a website or mobile app that provides great user experience could enhance the bank's revenue from the tech-savvy customer.

9. Traditional banks are facing severe competition from FinTech companies, which are financial technology firms that facilitate banking and financial services.

10. Launching new innovative products which are sometimes difficult to automate

11. Mergers and acquisitions and new government rules and regulations are difficult to incorporate into existing IT solution and customization of the software to continuous changes becomes tedious due to rigid software.

12. Many banks do not have expert in house infrastructure to support the changing business priorities

13. Risk Management/Mitigation helps in reducing intervention delays, continuous monitoring, fraud detection, smarter, deeper, faster controls.

\section{Bank Opportunities-}

1. Competitiveness -Banks can innovate simple products which are fairly priced and attract more customers to withstand the competition.

2. Marketing and Branding - Digital marketing with convergence of networks can strengthen the brand image.

3. Risk Management / mitigation, dashboards, Data Analytics, Fraud prevention , Real time operations , Process Dematerialisation, Digital signatures will enable the bank to be a market leader.

4. The digital Banking is concerned with 2 aspects both having digital technology underneath them.
A. A new thrilling experience to the customer who has a plethora of e-services available to him.
B. efficient, effective business model in the organisation

5. High speed, secured and transparent processing of transaction which results in wide spectrum of products and security proffered to the consumer at fair prices and high quality relationships with banks. 


\section{BASIC SERVICES OFFERED:}

1. Mobile banking -It refers to the use of smart phone or other cellular device to perform online banking tasks such as monitoring account balances, transferring funds between accounts , bill payment etc

2. Automated Teller Machine- It is electronic telecommunication device that facilitates customers to perform functions like

3. Internet Banking- Online banking, also known as internet banking, is an electronic payment system that enables customers of a bank or other financial institution to conduct a range of financial transactions through the financial institution's website. The online banking system will typically connect to or be part of the banking system operated by a bank and is in contrast to branch banking which was the traditional way customers accessed banking services.

4. RTGS- Real Time Gross Settlement

systems through which funds get transmittea by way of transfer of money or securities ${ }^{[1]}$ from one bank to another on a "real time" I.e. a payment transaction is not subjected to any waiting period, with transactions being settled as soon as they are processed and on a "gross" basis i.e. "Gross settlement" means the transaction is settled on one-to-one basis. Settlement means transactions undertaken once are irrevocable.

5. NEFT-National electronic funds transfer is a payment system in which individuals can electronically transfer funds from any bank branch to any individual having an account with any other bank branch in the country.

6. CTS-cheque Truncation System or Image-based Clearing System (ICS) is implemented by Reserve Bank of India (RBI), commencing in 2010, for faster clearing of cheques. In this system cheque images and magnetic ink character recognition (MICR) data are captured at the collecting bank branch and transmitted electronically.

7. IMPS- Immediate payment service IMPS is managed by the National Payments Corporation of India (NPCI) and offers an inter-bank electronic fund transfer service through mobile phones. Unlike NEFT and RTGS, the service is available 24/7 throughout the year including bank holiday

8. NACH - National Automated clearing house introduced by National Payments Corporation of India, is a centralised clearing service that aims at providing interbank high volume, low value

transactions that are repetitive and periodic in nature offering credit and debit service to corporate, banks, and financial institutions.

9. UPI- (Unified payment Interface)It is a unique interface that allows instant transfer of money from one bank account to another on a mobile platform leading to swift payment across banks. It will allow smart phones to substitute costlier POS machines. This technological government programmes expected a mass behavioural shift from cash to cashless transactions.

\section{Differing fortunes}

\begin{tabular}{|c|c|}
\hline UPI & BHIM \\
\hline AUGUST 2016 & DECEMBER 2016 \\
\hline $\mathbf{9 3 , 0 0 0}$ transactions & $\mathbf{4 3 , 0 0 0}$ transactions \\
\hline ₹3.1 crore value of transactions & ₹1.83 crore value of transactions \\
\hline 21 banks & $\begin{array}{l}5 \text { million downloads within a week } \\
\text { of launch }\end{array}$ \\
\hline JULY 2018 & JULY 2018 \\
\hline 23.5 crore transactions & 1.64 crore transactions \\
\hline$₹ 45,843$ crore value of transactions & $₹ \mathbf{6 , 6 9 2}$ crore value of transactions \\
\hline 114 banks & 32.4 million downloads till now \\
\hline
\end{tabular}

The shift towards UPI gathered pace, postdemonetisation, when there was a scarcity of cash in the market. Though payment interfaces such as NEFT and RTGS and the debit card have done their share of work, payment through UPI is safer and quicker enabling real-time, $24 X 7$ payments for the masses.

10. NUUP is National Unified USSD platform (USSD stands for unstructured supplementary service data) is a mobile banking service based on USSD.

11. Debit cards / smart cards, payment gateway RuPay launched in 2012 has challenged the duopoly of Visa and MasterCard in the payments gateway world.

As of June 2018, as per RBI record, there were 94.4 crore debit cards in India, out of which almost 50 crore are RuPay-powered debit cards amounting to $50 \%$ market share. Debit and credit card transactions still form the bulk of digital payments which can be validated from the following. RBI's data shows transactions through debit and credit cards in June 2018, wereas follows -There were 3.93 crore credit cards and 94.4 crore debit cards used in India including individual and corporate cards. The value of credit card transactions in the month of June 2018 is Rs. 46,629 crore and Debit card transactions in the same period went up by $33 \%$ to Rs. 3,15,627 crore. Percentage of Debit and credit card transactions to all digital transactions in terms of volume- $22.5 \%$

12. PPI- Prepaid payment instrument 
13. POS-point of sale - Businessman has to acquire a point-of-sale (PoS) machine for processing card payments from banks with which they already have an existing account. Each machine would have a fixed cost of approximately Rs 13,000 as well as monthly rentals of $\square 500-600$. Additionally, there would be an RBI-mandated merchant discount rate (MDR), which a merchant is charged for processing card transactions amounting to $0.75-1 \%$ and $2-2.5 \%$ per transaction on debit and credit cards respectively. A key feature of devices today is their 'interoperability', which means they are able to accept not just card payments, but also UPI-based payments, transfers from net banking, and 'tapto-pay' methods, e-wallets, Aadhar-enabled payments (AEPS) using near-field communication (NFC) technology.

14. BHIM - Bharat Interface for money, comparative analysis is as under

\begin{tabular}{|c|c|c|}
\hline & December 2016 & July 2018 \\
\hline Volume & 43000 & 1.64 crores \\
\hline Value & 1.83 crore & 6692 crores \\
\hline
\end{tabular}

BHIM transactions have risen to 1.64 crore (valued at $\square 6,692$ crore) in July 2018 , from 43,000 transactions (valued at $\square 1.83$ crore) in December 2016 when it was launched by Prime Minister Narendra Modi in New Delhi a month after demonetisation was announced.

The app offers payment solutions by accessing bank accounts and is linked to over 95 private and public sector banks. Within a week of BHIM's launch, the app had been downloaded more than 5 million times. BHIM to some extent has been usurped due to innovative products by companies such as Google (with its Tez payment system), Paytm and PhonePe.

Apparently BHIM was launched as stop-gap solution to improve the cash flow following demonetisation.

15. Paytm - With Paytm users can pay bills, buy movie tickets, pay school fees or buy digital gold, apart from shopping on Paytm Mall.

16. BPSS - Bharat bill payment syatem

17. Mobile wallet -The mobile wallets dominated the market immediately after the demonetisation.

18. The banks have also implemented e-kyc (know your customer) system.

\section{Analytics -}

1. Today mobile banking and mobile wallets are fastest growing options in payment industry

2. As per the data of 5 banks in December 2016

A. NEFT, CTS, NACH and cards account for bulk of transactions by volume $(76 \%)$

B. RTGS, NEFT, CTS account for $(89 \%)$ of transactions by value.

3. It is clear that increased smart phone users in India will grow digital baking in India National Automated Clearing House, or NACH, introduced by National Payments Corporation of India, is a centralised clearing service that aims at providing interbank high volume, low value transactions that are repetitive and periodic in nature. Offering credit and debit service to corporate, banks, and financial institutions, exponentially.

4. Mere technological advancement will not shift the traditional banking pattern to digital banking in India because basically India is a cash economy , prevalence of digital illiteracy and reluctance of large section of population to go for digital payments. The design and delivery of various financial services channels is influenced by accelerated technological advancements (online transaction by way of internet and mobile phone) shift in customer preferences and regulating infrastructure adopting to digitalisation

5. The Pradhan Mantri Jan DhanYojana by way of 220 million cards and 282 million accounts (as per 29.3.2017) has provided infrastructure for universal access to banking. The unbanked population has reduced from 577 million to 233 million.

6. In 2018, HDFC Bank has also introduced newer products such as digital loans against shares and loans against mutual funds. If there is an emergency, instead of redeeming mutual funds, the bank will offer a loan in three minutes through net banking, holding the customer's mutual fund account as collateral.

7. The digital journey for banks like state bank of India and ICICI has been holistic. ICICI Bank has invested in FingPay and used some of its solutions towards its Eazypay app. SBI has tied up with Reliance Jio for integrating its digital banking app Yono with MyJio app. Yono (you only need one) has 2.5 million users and enables users open an SBI account digitally, transfer funds and get a pre-approved personal loan digitally. 
8. The most interesting app of HDFC - EVA (electronic virtual assistant), an AI-powered banking chatbot, has been configured for voice through Google Assist and Amazon's Alexa. EVA has answered more than 8 million queries from a million customers and is now integrated with the bank's interactive humanoid IRA (interactive robotic assistant).

9. HDFC Bank has collaborated with Google Tez to operate its UPI handle while, on Facebook, it has tied up with Niki.ai, a Ratan Tata-backed fintech, to create a chat platform, perform ecommerce transactions and also pay bills or buy insurance through Facebook Messenger. The bank's expense tracker on mobile is with Money View while it's Digital Command Centre-where the bankuses internet and all social media platforms-were built in collaboration with a LocoBuzz. The bank also works with assessment technology provider Talview, which helps it carry out interviews on video, as part of its HR policy.

\section{Futuristic features -}

Predictive banking - The wearable technology like smart watches, smart eye ware, gesture controlled devices, sensors embedded in cooking utensils cars can enable the bank to create innovative products for its customers. Banks will be part of everyday routine activities of all human beings. As there is infinite potential for banks and fintech companies to explore and innovate on different fronts eg. Banks can offer customised insurance products based on health data (pulse rate, blood pressure, sleeping time, daily physical exercise, calorie and nutritional intake) which will be captured from fitness band worn by humans.

Digitalisation in banking is adoption of existing and evolving technological changes efficiently and effectively in the internal business processes of banks as well as working towards superior customer's relationships and experience. The futuristic innovative technology is changing the face of bank's business model.

Revolutionalising from traditional banking to state of art digital banking has ultimately paved way for customer satisfaction and value through infinite operational efficiency. Banks have started with reduction in number and size of branches (both number of units and size of existing facilities) and replacing with ATM's, digital kiosks for account operating, and customer enquiry thereby heightening the digital maturity. Today traditional banks differ from digital market entrants who offer end to end online process offering customers to open a new account using digital channels and some value added services like digital document safekeeping, access to financial news, digital investing, and personalised digital alerts, digital saving tools, online chat, and social media banking

$>$ BaaS - Banking as a Service (allows for third party integration)

$>$ BaaP - Banking as a Platform (for integrating core systems with software)

Cloud-based Infrastructure (allows less dependence on IT staff)

White Label Banking (such as joint-branded credit cards $)^{[14]}$

These solutions are built on enhanced technical architectures as well as different business models.

\section{CONCLUSION:-}

With the increasing usage of smart phones and emerging technologies, digitization of banking sector is inevitable, to escalate up to the increasing expectations of the world. It indeed reduced human errors and increased convenience of general public in banking operations.There is no doubt that pros of digitization are outweighing the cons but the fact that cyber threats are also on the rise, banks must be very careful and should be prepared to handle cyber attacks.

\section{REFERENCES}

1. www.forbesindia.com

2. www.economictimes.indiatimes.com

3. www.thebanker.com

4. www.researchgate.net

5. www.capitaworld.com 